\title{
DIREITO À MORADIA: UM PARALELO ENTRE A REALIDADE BRASILEIRA E
}

\section{A INTERNACIONAL}

\author{
Cláudio Antônio Klaus Júnior ${ }^{1}$ \\ Rafael Reis ${ }^{2}$ \\ Recebido em 08/06/2021 \\ Aceito em 23/08/2021
}

\section{RESUMO}

A terra e os direitos relacionados a ela têm sido tema de debate desde os primórdios da civilização humana, encontrando informações sobre tal direito desde as leis civis da Babilônia. Vários tratados foram escritos ao decorrer da história que tratavam da utilização, regulamentação e distribuição deste bem. O presente artigo tem como objetivo demonstrar, através de uma pesquisa bibliográfica, como o assunto é tratado no âmbito internacional, para fins do presente trabalho especificamente da Índia, Estados Unidos, África do Sul, Noruega e Nova Zelândia lidam com o direito à moradia e como o Brasil tem feito isso, além de elucidar os conceitos de direito à moradia e direito à moradia adequada. $\mathrm{O}$ estudo conclui que somente o tempo poderá dizer se as medidas recentes tomadas no ordenamento brasileiro serão suficientes para permitir que o direito à moradia seja efetivado no país, entretanto, que no nível de segurança jurídica, o Brasil demonstra em sua legislação o direito à moradia como direito fundamental para seus habitantes.

PALAVRAS CHAVE: Direito à moradia. Direitos Humanos. Justiça social.

\section{THE RIGHT TO HOUSING: A PARALLEL BETWEEN BRAZILIAN AND INTERNATIONAL REALITY}

\begin{abstract}
The land and the rights related to it have been the subject of debate since the dawn of human civilization, finding information about such rights since the civil laws of Babylon. Several treatises were written throughout history that dealt with the use, regulation and distribution of this good. This article aims to demonstrate, through a bibliographical research, how the subject is treated at the international level, for the purposes of this work, specifically India, the United States, South Africa, Norway and New Zealand deal with the right to housing and how Brazil has done this, in addition to elucidating the concepts of the right to housing and the right to adequate housing. The study concludes that only
\end{abstract}

\footnotetext{
${ }^{1}$ Bacharel em Relações Internacionais do Centro Universitário UNINTER. Graduando em Direito da Universidade Alto Vale do Rio do Peixe - UNIARP. juniorklaus8@ gmail.com.

2 Doutor em Sociologia Política (UFSC, 2017), Mestrado em Relações Internacionais (UFRGS, 2008), Especialização em Educação, Meio Ambiente e Desenvolvimento (UFPR, 2003), e Bacharelado em Relações Internacionais (UTP, 2002). Participou do Comitê de Assessoramento para o ENADE (2015) do Instituto Nacional de Estudos e Pesquisas Educacionais Anísio Teixeira. Professor do Conselho Editorial do periódico científico Relações Internacionais do Mundo Atual (2009-2016). Membro do Conselho de Comércio Exterior e Relações Internacionais (CONCEX-PR) desde 2012, e do Conselho Acadêmico do Instituto de Relações Internacionais do Paraná (IRIP) desde 2018. Atualmente é professor vinculado aos cursos superiores de Relações Internacionais e Ciência Política da UNINTER.
} 
time will be able to tell whether the recent measures taken in the Brazilian legal system will be sufficient to allow the right to housing to be implemented in the country, however, at the level of legal certainty, Brazil demonstrates in its legislation the right to housing as a fundamental right for its inhabitants.

Keywords: Right to housing. Human rights. Social justice.

\section{INTRODUÇÃO}

A terra ocupa um papel de destaque na sociedade e sua ocupação, destinação e regulação é quase tão antiga quanto a própria história da humanidade (MACHADO, 2017). Globalmente, mais de 1,6 bilhão de pessoas vivem em moradias inadequadas, enquanto mais de 100 milhões estão desabrigadas (CHAUNDHRY, 2019).

O direito de moradia é, basicamente, o direito de ter um lar. Tal direito tornou-se um direito humano universal, aceito e aplicável em todas as partes do mundo, no ano de 1948, com a Declaração Universal dos Direitos Humanos. Tal marco legislativo fez com que tal questão relacionada com a dignidade da pessoa humana se torne um direito positivo, e assim, como tratado internacional, se torna disciplina para o ordenamento da sociedade.

O presente trabalho apresenta um breve panorama sobre a questão em cinco países, cada um representando um dos continentes, não pretendendo esgotar o assunto, pelo contrário, gerar o interesse e a inquietação para o estudo e pesquisas mais aprofundado do tema por parte de outros pesquisadores das ciências sociais aplicadas.

A problemático do trabalho envolve a compreensão de que o Brasil enfrenta diversos desafios em relação à garantia do direito à moradia, e o presente trabalho visa apresentar e responder como é o panorama internacional em relação ao tema, como outras nações lidam com os desafios relacionados ao tema e também qual é a atual situação do Brasil.

Objetivando realizar um estudo que possibilite compreender, de modo geral, como o Brasil tem se colocado nos panoramas mundiais em relação a garantia do direito à moradia, o presente trabalho tem como objetivos específicos: 1) Possibilitar a compreensão ampla de tratados internacionais e legislação nacional em relação ao tema do direito humano à moradia; 2) Dissertar e exemplificar as principais diferenças e situações que ocorrem no Brasil em relação às outras nações; e 3) Apresentar conclusões sobre a posição do Brasil em um panorama internacional relacionado ao cumprimento de tratados e garantia do direito à moradia.

Sanghera, Satybaldieva (2012); Machado (2017) e Ribeiro (2019) apresentam importantes detalhes na busca da compreensão do direito à moradia. $\mathrm{O}$ trabalho utiliza-se da pesquisa bibliográfica, verificando diferentes publicações científicas e documentos jurídicos 
que abordam diretamente a questão do direito à moradia em âmbito nacional e internacional.

Sobre a situação no Brasil, Haglund; Stryker (2015, p. 14) leciona que "apesar dos investimentos consideráveis do governo federal, o Brasil luta contra um enorme déficit habitacional e milhões de pessoas em todo o país vivem em assentamentos irregulares”. Assim, faz-se necessário realizar uma análise que demonstre comparações e aspectos relevantes do avanço nos desafios relacionados ao direito à moradia no Brasil em comparação a outras nações.

Também ciente das diferenças que não se limitam ao ordenamento jurídico, cultura e PIB de cada localidade, o presente trabalho apenas destaca detalhes superficiais sobre as realidades mencionadas.

\section{O DIREITO À MORADIA}

Conforme contextualiza MACHADO (2017b), a terra ocupa um papel de destaque na sociedade. O contexto histórico demonstra que a sua destinação e regulação foi se alterando com o passar dos séculos e de forma diferente em diferentes sociedades. $\mathrm{O}$ autor ainda menciona que a noção do homem de ter direitos sobre um espaço exclusivo de terra é tão antiga quanto o ele próprio, sendo encontradas referências ao direito de propriedade nas leis civis da Babilônia, no ano 5.000 a.C (MACHADO, 2017a).

$\mathrm{O}$ direito à moradia abrange uma miríade de direitos garantidos pela legislação nacional e também por tratados internacionais. É um direito inato ao ser humano e surge juntamente com seu nascimento, configurando assim um direito humano universal e sua efetivação e garantia tem um histórico de desigualdades e problemáticas, assim como proteções (MACHADO, 2017a)

Neste ponto, faz-se necessário mencionar os conceitos de direito natural e direito positivo. $\mathrm{O}$ direito natural, como direito puramente racional, só teria uma existência ideal, como o próprio estado de natureza. O direito positivo, também chamado de estatutário, é aquele estabelecido pela vontade de um legislador e constituído pelas leis [empiricamente existentes] num determinado lugar e num determinado tempo. Conforme conceitua Kant, "o primeiro é o direito em potência, o segundo é o direito em ato.” (ESTEVES, 2012).

O direito natural é visto pela generalidade e impraticabilidade, trata-se do direito que está relacionado à moral e não está necessariamente escrito e codificado. Já o direito positivo é justamente aquele que tornou-se, em termos mais práticos, "lei”. Assim, no contexto do direito 
à moradia, quando se coloca na perspectiva natural, fica claro que é moral e necessário para que haja uma vida digna, um lar. Enquanto tal compreensão é importante, não é possível de ser aplicada, de se fazer cumprir ou impor. Assim, quando tal necessidade para moradia, tal necessidade se tornou texto legislativo/regimental e então tornou-se direito positivo.

Elucidando sobre o tema:

O direito à moradia transcende o direito de ter casa própria, pois não se confunde com o direito à propriedade. Moradia requer ocupar uma habitação com dimensões adequadas, em condições de higiene e conforto capazes de preservar a intimidade e a vida privada. Pressupõe respeito à dignidade da pessoa humana, de modo que no local da habitação é preciso haver saneamento básico, transporte, áreas de lazer, água potável e energia (GERALDELLI, 2019, p. 5).

Assim, alguns dos principais tratados e instumentos que difundiram de forma jurídica (ou seja, dirieto positivo) o reconhecimento do direito à moradia como direito humano fundamental são o Pacto Internacional sobre os Direitos Econômicos, Sociais e Culturais; a Convenção Internacional sobre a Eliminação de Todas as Formas de Discriminação Racial; a Convenção Sobre a Eliminação de Todas as Formas de Discriminação Contra a Mulher e a Convenção sobre os Direitos das Crianças (MACHADO, 2017a).

Logo, não existem dúvidas sobre o reconhecimento do direito à moradia, entretanto, a realidade demonstrada parece estar em conflito com tal proteção. O Relatório das Nações Unidas-Habitat (2003), The Challenge of Slums, afirma que quase um bilhão de pessoas ou 32 por cento da população urbana do mundo, vivem em favelas, a maioria delas nos países em desenvolvimento (SANGHERA, SATYBALDIEVA, 2012).

Além de simples, o direito à moradia, que em si encara difíceis realidades, também se refere ao direito à moradia adequada e à dignidade da pessoa humana, tendo como componentes essenciais:

\footnotetext{
- Segurança jurídica da posse - para garantir a moradia contra despejos e deslocamentos forçados e outros tipos de ameaças à posse;

- Disponibilidade de serviços e infra-estrutura - a moradia será sempre mais adequada, quanto mais fácil seja o acesso à água potável, energia, saneamento básico e tratamento de resíduos, transporte e iluminação pública;

- Custo acessível da moradia - a moradia será sempre mais adequada, quanto mais os gastos com a moradia sejam proporcionais à renda, asseguradas as demais exigências para uma Moradia Adequada;

- Habitabilidade - a moradia será sempre mais adequada, quanto mais ofereça condições físicas e de salubridade adequadas;

- Acessibilidade - às políticas habitacionais visarão sempre mais à Moradia Adequada para todos, quanto mais contemplem os grupos mais vulneráveis; - Localização - a moradia será sempre mais adequada, quanto mais adequadamente esteja inserida na cidade, com acesso adequado às opções de emprego, transporte público eficiente, serviços de saúde, escolas, cultura e lazer;

- Adequação cultural - a moradia será sempre mais adequada, quanto mais
} 
respeite a diversidade cultural e os padrões habitacionais oriundos dos usos e costumes das comunidades e grupos sociais (SAULE JÚNIOR, 2005, p.11).

Tal menção foi assegurada pela Assembleia Geral da ONU que declarou em 2010 que o acesso à água limpa e segura e ao saneamento básico são direitos humanos fundamentais. Nessa abordagem, o Objetivo do Desenvolvimento Sustentável (ODS) 11 rege: "Tornar as cidades e os assentamentos humanos inclusivos, seguros, resilientes e sustentáveis". Assim, verifica-se que a temática é de tal importância que se coloca em diversas listas de prioridade, como mencionado aqui, um dos ODS que são

\begin{abstract}
um apelo global à ação para acabar com a pobreza, proteger o meio ambiente e o clima e garantir que as pessoas, em todos os lugares, possam desfrutar de paz e de prosperidade. Estes são os objetivos para os quais as Nações Unidas estão contribuindo a fim de que possamos atingir a Agenda 2030 no Brasil (NAÇÕES UNIDAS, 2021).
\end{abstract}

No próximo ponto, o texto apresenta o cenário internacional e depois dele, a realidade brasileira, de antemão, pode-se observar que há uma dissonância entre o idealizado por lei e a realidade. Como visto anteriormente, Geraldelli (2019) leciona que o direito à moradia transcende o direito de ter casa própria e requer uma habitação com dimensões adequadas, em condições de higiene e conforto, pressupondo respeito à dignidade. Sabe-se, entretanto, que a realidade (pelo menos em cenário nacional) ainda não contempla tal realidade que é demonstrada em texto de lei como sendo o ideal.

\title{
3 O DIREITO À MORADIA NO CENÁRIO INTERNACIONAL
}

Para fins do escopo do presente trabalho, uma breve contextualização do tema será apresentada em países que representam os continentes, nomeadamente, a Índia, Estados Unidos da América, África do Sul, Noruega e Nova Zelândia.

\section{1 ÍNDIA}

Localizada no Sul da Ásia e com mais de 1,366 bilhão de habitantes, a Índia é o segundo país mais populoso do mundo. Conhecido por sua riqueza comercial e cultural de grande parte da sua longa história.

O sistema jurídico da Índia é o da Common Law. Assim, a principal forma dos tribunais de julgar é através do precedente. Desta feita, para uma melhor compreensão, ainda que superficial, da realidade local e das inclinações das cortes na defesa do direito à moradia ou de outros direitos conflitantes, pode-se verificar alguns dos casos relacionados ao tema.

O país tem casos emblemáticos, para fins do presente trabalho, o caso K. Chandru v. 
Estado de Tamil $\mathrm{Nadu}^{3}$, vem ao encontro deste objeto de estudo. Neste caso, o Estado de Tamil Nadu promulgou a Lei de Áreas de Favela Tamil $\mathrm{Nadu}^{4}$ para erradicar favelas que, segundo o pedido do Estado, "poderiam se tornar uma fonte de perigo para a saúde pública ou saneamento" (LAWTEACHER, 2013).

O Tribunal, neste caso, reconheceu a relação entre o direito à subsistência e o direito à moradia. A decisão final ainda menciona que "ações estão sendo tomadas com o objetivo de melhorar as áreas de habitação irregulares e, onde não podem ser melhoradas, deverão ser oferecidas acomodações alternativas aos moradores da favela, antes de serem despejados" (LAWTEACHER, 2013).

Em outro caso, Chameli Singh v. Estado de Uttar Pradesh ${ }^{5}$, foi sustentado que o direito à vida garantido em qualquer sociedade civilizada implica o direito à alimentação, água, meio ambiente decente, educação, assistência médica e abrigo. (LAWTEACHER, 2013).

Assim, pode-se constatar que leis de fato protegem o direito à moradia. Entretanto, o texto de lei, assim como no cenário anteriormente posto sobre os tratados internacionais, parecem destoar da realidade. Em uma publicação de 2019, a autora Shivani Chaudhry escreveu sobre o direito à moradia na Índia. Em seu texto, Shivani explica que a crise imobiliária naquele país é caracterizada por diversos fatores que impedem o cumprimento do tratado que ratifica o direito à moradia no país. Segundo a autora, a política fundiária, a aguda escassez de moradias de baixo custo, a prevalência de assentamentos inadequados [e irregulares] com insegurança de posse e condições de vida péssimas, despejos forçados e a especulação imobiliária são apenas alguns dos problemas que o país enfrenta (CHAUNDHRY, 2019).

A autora ainda menciona: "A Índia poderia adotar uma política semelhante (à do Brasil) e alterar as leis relacionadas à usucapião, que atualmente não oferece posse segura para os pobres, mesmo quando eles vivem em um determinado local por décadas" (CHAUNDHRY, 2019). Embora exista a Política Nacional de Habitação da Índia desde 1988, não existe uma Política Urbana Nacional em vigor (LAWTEACHER, 2013).

\subsection{ESTADOS UNIDOS DA AMÉRICA}

Com 328,2 milhões de habitantes e localizado na América do Norte, os Estados Unidos da América é um país conhecido por sua posição de liderança na economia mundial. Os Estados Unidos, assim como a Índia, têm a common law como sistema jurídico.

\footnotetext{
${ }^{3}$ Tradução livre de "K. Chandru Etc.Etc vs State Of Tamil Nadu \& Ors"

${ }^{4}$ Tradução livre de "Tamil Nadu Slum Areas Act"

${ }^{5}$ Tradução livre de "Chameli Singh vs State of Uttar Pradesh"
} 
Baseado no Relatório do Comitê Internacional de Direitos Humanos da New York Bar Association: Avançando o Direito à Moradia nos EUA, as preocupações com moradia adequada começaram durante a Grande Depressão, e foi então que a estrutura básica para as leis de moradia começaram a se formar no país (NEW YORK CITY BAR, 2016).

No entanto, os Estados Unidos, embora seja signatário de várias convenções internacionais de direitos humanos, não ratificou nenhuma convenção que tornaria aplicável o direito à moradia; e os Estados Unidos não reconhecem explicitamente o direito à moradia adequada em sua Constituição ou na lei federal (NEW YORK CITY BAR, 2016).

Da mesma forma, os estados tentam resolver as questões habitacionais por meio de programas regulatórios e, muitas vezes, vão além das proteções federais existentes. Infelizmente, essa abordagem fragmentada está muito aquém das proteções que seriam fornecidas sob um direito codificado à moradia adequada. As fragilidades dessa abordagem nos níveis federal e estadual são evidenciadas, por exemplo, por meio da discriminação habitacional e de respostas ineficazes a desastres naturais (NEW YORK CITY BAR, 2016).

Os Estados Unidos implementaram vários programas que apoiam o direito à moradia por meio de outros direitos reconhecidos. Por exemplo, o Departamento de Habitação e Desenvolvimento Urbano dos Estados Unidos (“HUD”) oferece um Programa de Unificação de Família que fornece vouchers de Escolha de Moradia para famílias se a falta de abrigo for o principal motivo de uma criança ser removida ou não devolvida aos pais (NEW YORK CITY BAR, 2016).

Além disso, o governo e quatro organizações filantrópicas iniciaram uma parceria de 35 milhões de dólares para criar moradias de apoio para famílias sem-teto, a fim de evitar que crianças entrem no sistema de assistência social. Outras reformas tentam realizar esses direitos sem qualquer apoio para o direito de habitação. Esses programas e reformas são importantes para a realização desses outros direitos, mas não devem diminuir a importância do direito à moradia como um elemento fundamental do direito próprio (NEW YORK CITY BAR, 2016). Falando sobre a situação atual no país:

In 2013 there were an estimated 610,042 homeless people in the United States. The UN Human Rights Committee has expressed concern "that some $50 \%$ of homeless people are African American although they constitute only $12 \%$ of the US population." Although there are extensive shelter networks, approximately $40 \%$ of the homeless population in the United States remains unsheltered, meaning that these individuals live and sleep in areas that are not intended for human habitation (NEW YORK CITY BAR, 2016, p. 13) ${ }^{6}$.

\footnotetext{
${ }^{6}$ Tradução livre para o português: "Em 2013, havia cerca de 610.042 desabrigados nos Estados Unidos. O Comitê de Direitos Humanos da ONU expressou preocupação "que cerca de $50 \%$ dos sem-teto são afro-americanos, embora constituam apenas $12 \%$ da população dos EUA". Embora existam extensas redes de abrigos,
} 
Assim, pode-se verificar que o país também enfrenta questões relacionadas ao direito à moradia, demonstrando que existe uma dificuldade mundial em sua efetivação. Assim, mesmo um país rico como os EUA (com PIB de 21,43 trilhões USD) também enfrenta tais dificuldades.

Destaca-se ainda que, no contexto apresentado, o filme 'Nomadland - Sobreviver na América', vencedor do Oscar 2021, mostra a realidade do país, especialmente no momento pós crise de 2008. Na obra, verifica-se que a crise habitacional do país no contexto que é mostrado levou pessoas a deixarem suas residências e habitarem seus veículos como "nômades modernos".

\section{3 ÁFRICA DO SUL}

A África do Sul é um país situado na extremidade sul do continente africano, com população de 58,56 milhões de pessoas. Possui um sistema jurídico 'híbrido' ou 'misto', formado pelo entrelaçamento de uma série de tradições jurídicas distintas: um sistema de Civil Law herdado dos holandeses, um sistema de Common Law herdado dos britânicos e um sistema de direito consuetudinário herdado de africanos indígenas.

Para uma breve contextualização histórica, é necessário compreender que na África do Sul sob o apartheid, a segregação habitacional era imposta por lei, o que significava que os não-brancos não podiam viver em áreas designadas para brancos. Pouca moradia foi fornecida para os africanos, com os difíceis requisitos legais de posse nas áreas urbanas sendo condicionados ao emprego urbano e a longo prazo ou somente com a posse do aluguel, mas nunca foram autorizados a possuir casas. As reformas políticas de 1983 introduziram os negros à mais locais e permitiram a venda de algumas casas alugadas (SOUTH AFRICAN HUMAN RIGHTS COMMISSION, 2016).

Por fim, a Constituição da República da África do Sul (1996) tornou o direito à moradia um direito fundamental, conforme definido nos artigos 25, 26 e 28 da Carta-Magna do país:

Artigo 25. Propriedade:

$[\ldots]$

(6) Uma pessoa ou comunidade cuja posse de terra é legalmente insegura como resultado de leis ou práticas discriminatórias do passado tem direito, na medida prevista por uma Lei do Parlamento, a posse legalmente segura ou a reparação comparável. (7) Uma pessoa ou comunidade despojada de propriedade após 19 de junho de 1913 como resultado de leis ou práticas discriminatórias do passado tem direito, na medida prevista por uma Lei do Parlamento, seja à restituição dessa propriedade ou a uma reparação equitativa $[\ldots]$

aproximadamente $40 \%$ da população sem-teto nos Estados Unidos permanece sem abrigo, o que significa que esses indivíduos vivem e dormem em áreas que não são destinadas à habitação humana." 
Artigo 26. Habitação: (1) Toda pessoa tem direito ao acesso a uma moradia adequada. (2) O estado deve tomar medidas legislativas e outras razoáveis, de acordo com seus recursos disponíveis, para alcançar a realização progressiva desse direito. (3) Ninguém pode ser despejado de sua casa, ou ter sua casa demolida, sem uma ordem do tribunal feita após considerar todas as circunstâncias relevantes. Nenhuma legislação pode permitir despejos arbitrários. [...]

Artigo 28. Crianças:

(1) Toda criança tem direito - a [...] abrigo (LAWTEACHER, 2013). ${ }^{7}$

Assim, várias proteções legislativas estão disponíveis no país para a proteção e efetivação do direito, além da garantia para a justiça social.

Para entender a situação atual do país:

Em junho de 2013, a carteira de imóveis residenciais era de 2,1 milhões de unidades (afetando mais de oito milhões de pessoas). Em 2012, 54,5 por cento das famílias viviam em assentamentos informais. Em termos de alcançar uma sociedade integrada não racial, a África do Sul ainda é vista como uma "sociedade grosseiramente desigual em que à população de maioria pobre (esmagadoramente negra) é desproporcionalmente negada oportunidades de habitação adequada e amenidades básicas." Foi relatado que, apesar do compromisso do governo em realizar o direito à moradia por meio de uma série de políticas e programas, "muitas famílias pobres continuam sem ter acesso a alguma forma de moradia adequada, muitas vezes tendo que viver em condições difíceis em assentamentos informais e favelas no centro da cidade em edifícios e sujeitos a risco constante de despejo [...] (CHENWI, 2015, p. 69). ${ }^{8}$

Casos emblemáticos ocorridos ao decorrer da história do país marcaram sua legislação, como por exemplo, o dos Residentes de Joe Slovo Community v Thubelisha Home ${ }^{9}$, em que o Tribunal Constitucional determinou que o Estado era obrigado a fornecer abrigo temporário para pessoas que foram despejadas ou que enfrentam despejo iminente e não conseguiram encontrar abrigo, já que a prioridade absoluta deve ser o princípio da dignidade da pessoa

\footnotetext{
${ }^{7}$ Original: "Article 25. Property: [...] (6) A person or community whose tenure of land is legally insecure as a result of past racially discriminatory laws or practices is entitled, to the extent provided by an Act of Parliament, either to tenure which is legally secure or to comparable redress. (7) A person or community dispossessed of property after 19 June 1913 as a result of past racially discriminatory laws or practices is entitled, to the extent provided by an Act of Parliament, either to restitution of that property or to equitable redress [...] Article 26. Housing: (1) Everyone has the right to have access to adequate housing. (2) The state must take reasonable legislative and other measures, within its available resources, to achieve the progressive realisation of this right. (3) No one may be evicted from their home, or have their home demolished, without an order of court made after considering all the relevant circumstances. No legislation may permit arbitrary evictions. [...] Article 28. Children: (1) Every child has the right - to [...] shelter."

${ }^{8}$ Original: "In June 2013, the housing backlog reportedly stood at 2.1 million units (affecting over eight million people). In 2012, 54.5 percent of households were living in informal settlements. In terms of achieving a nonracial integrated society, South Africa is still seen as a "grossly unequal society in which the (overwhelmingly black) poor majority population is disproportionately denied adequate housing opportunities and basic amenities." It has been reported that despite the government's commitment to realize housing rights through the range of policies and programmes, "many poor households remain unable to access some form of adequate housing, often having to live in difficult conditions in informal settlements and inner city 'slum buildings' and subject to the constant risk of eviction."

${ }^{9}$ Tradução livre de "Residents of Joe Slovo Community v Thubelisha Home"
} 
humana (SOUTH AFRICAN HUMAN RIGHTS COMMISSION, 2016).

Ainda, sobre o caso, a comunidade assentada na Cidade do Cabo (Joe Slovo Community, mencionada acima) peticionou o Tribunal na tentativa de impedir o despejo de suas casas a fim de facilitar o desenvolvimento habitacional, com o objetivo de melhorar o assentamento informal. A comunidade não era contra a reforma em si, mas a abordagem feita a ela e as preocupações em torno da distribuição de moradias após o desenvolvimento e a realidade de que nem todos os moradores se beneficiariam com as casas que seriam construídas no assentamento foi o principal problema enfrentado pelos moradores do local. Outrossim, o governo não estava disposto a fazer uma atualização in situ, o que não implicaria em despejo (já que o Estado era obrigado a fornecer abrigo temporário) (CHENWI, 2015).

Não obstante, as heranças do apartheid permanecem evidentes, por exemplo, na habitação de cidades como a Cidade do Cabo, que concentra pessoas majoritariamente por sua cor:

Figura 1: "WHY SOUTH AFRICA IS STILL SO SEGREGATED”

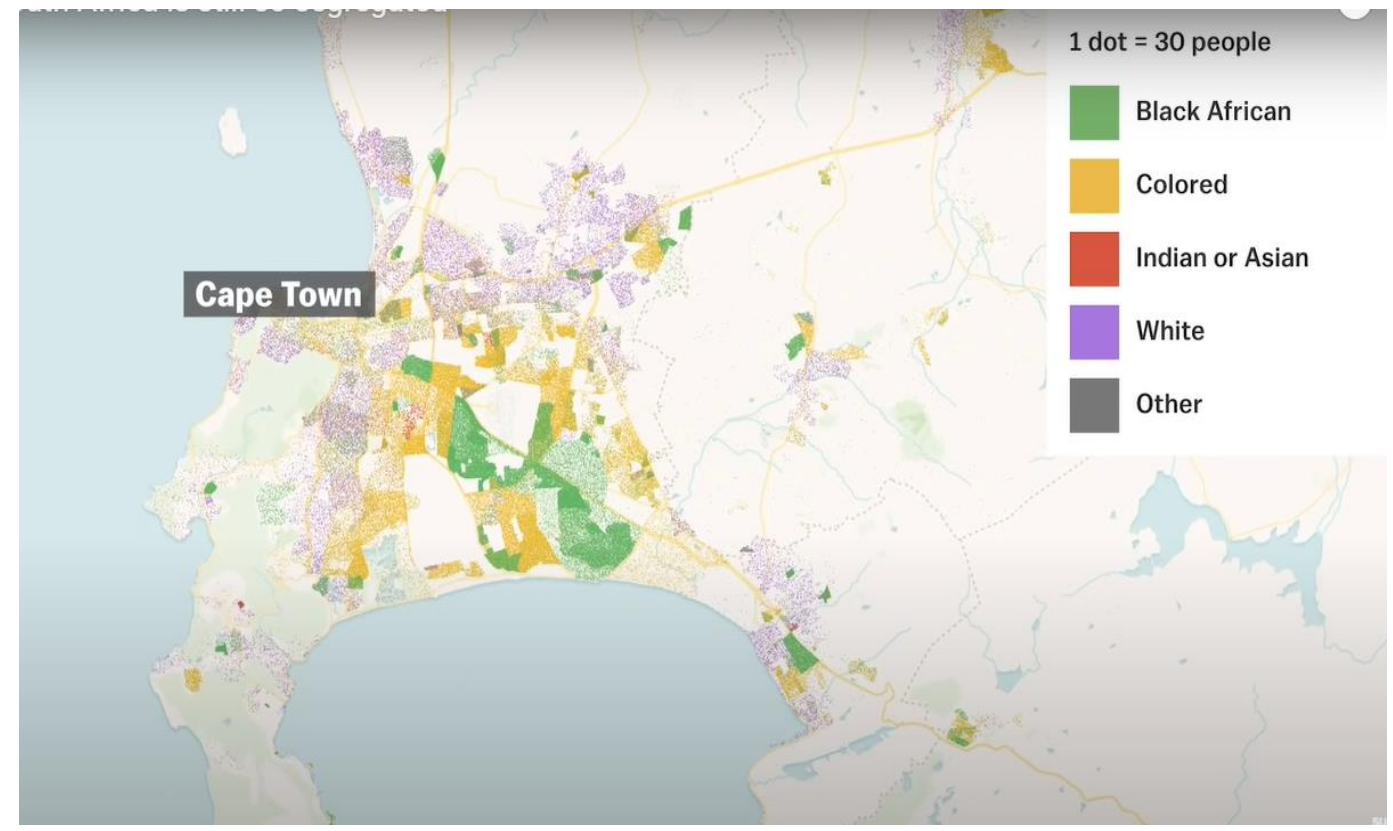

Habitação na Cidade do Cabo dividida por autodeclaração em censo.

Fonte: VOX, 2021

Para uma compreensão mais detalhada da evolução jurisprudencial relacionada ao direito à moradia no país, recomenda-se a leitura do artigo de Lucy A. Williams publicado na Columbia Human Rights Law Review ${ }^{10}$.

\footnotetext{
${ }^{10} \mathrm{O}$ texto poderá ser encontrado no link: https://repository.library.northeastern.edu/files/neu:336949/fulltext.pdf.
} 


\subsection{NORUEGA}

A Noruega é um país da Europa, com população de 5,328 milhões de pessoas e sistema jurídico misto de Civil, Common e Customary Law.

De acordo com a lei norueguesa, não existem disposições legais que estabelecem o direito à moradia. É dever da autoridade municipal, de acordo com a Lei do Serviço Social, fornecer abrigo temporário e moradia para pessoas que não possam obter uma para si (ESCRITÓRIO DO ALTO COMISSÁRIO DAS NAÇÕES UNIDAS PARA OS DIREITOS HUMANOS, 2015).

Em 2014, as estatísticas da Noruega estimaram 122.000 pessoas em 45.000 famílias como "desfavorecidas no mercado de habitação", totalizando 2,5 por cento da população na Noruega (ESCRITÓRIO DO ALTO COMISSÁRIO DAS NAÇÕES UNIDAS PARA OS DIREITOS HUMANOS, 2015).

Na Noruega, os sem-teto já foram grupo-alvo de duas iniciativas nacionais: "o projeto de moradores de rua" (2000-2004) e a estratégia "obtenção de moradia para si” (2005-2007). Em 2014, o governo lançou uma nova estratégia que unificou as iniciativas de combate à falta de moradia, à exclusão habitacional e à desvantagem no mercado imobiliário (ESCRITÓRIO DO ALTO COMISSÁRIO DAS NAÇÕES UNIDAS PARA OS DIREITOS HUMANOS, 2015).

\subsection{NOVA ZELÂNDIA}

Localizada na Oceania, a Nova Zelândia é um país com 4,917 milhões de habitantes. O sistema jurídico adotado pela Nova Zelândia é a Common Law. A Nova Zelândia reconhece uma série de tratados internacionais para proteção do direito à moradia. No país, o Estado tem a obrigação de efetivar este direito. Enquanto o direito à moradia é reconhecido, não há uma política em relação aos moradores de rua e sem-teto no governo central do país (FAHRA, 2020).

É amplamente reconhecido, inclusive dentro do governo, a existência de uma crise de habitação na Nova Zelândia e que está sendo vivenciada de forma mais aguda por grupos específicos, incluindo: Māori, povos do Pacífico e outras comunidades étnicas, pessoas com deficiência, pais solteiros (principalmente mães solteiras), jovens e crianças, e aqueles que vivem na pobreza (FAHRA, 2020).

No início de 2009, os ministros do país concordaram com um programa de trabalho para tratar de questões relacionadas a crises, moradia transitória e de longo prazo para os mais necessitados, incluindo pessoas com deficiência e aqueles que fogem da violência doméstica. Muitos motivos foram dados para a crise imobiliária, incluindo a falta de oferta de moradias 
populares e acessíveis, oferta limitada de moradias públicas e investimento especulativo estrangeiro em imóveis residenciais (FAHRA, 2020).

O problema relacionado à efetivação do direito à moradia vem de longa data; inclusive, até o final da década de 1980, várias formas de assistência financeira do Estado permitiam que famílias de baixa renda construíssem ou adquirissem casas. No entanto, com o tempo, isso foi reduzido a volumes insignificantes. Durante as décadas de 1960 e 1970, aproximadamente 30\% (trinta por cento) de todas as novas construções eram acessíveis para famílias de baixa renda. Em 2014, no entanto, isso havia caído para apenas 5\% (cinco por cento) (FAHRA, 2020).

\section{O DIREITO À MORADIA NO BRASIL}

O Brasil tem uma população de 211 milhões de pessoas, um dos maiores países do mundo e com ordenamento jurídico de Civil Law.

O país teve diferentes constituições e uma História que é marcada, primeiramente, pela exploração e pela escravização dos povos nativos e depois, no decorrer de seu desenvolvimento e História, a escravização de outros povos trazidos ao país. A problemática da moradia no Brasil é tema que remonta aos seus cinco séculos de História (MACHADO, 2017a).

A questão da moradia no país sempre foi difícil. Como mencionado pela escritora Djamila Ribeiro (2019, p. 10): “a Lei de Terras de 1850 [...] extinguiu a apropriação de terras com base na ocupação e dava ao Estado o direito de distribuí-las somente mediante a compra".

Ribeiro (2019, p. 10) também menciona que "ex-escravizados tinham enormes restrições, pois só quem dispunha de grandes quantias poderia se tornar proprietário. A lei [...] facilitou o acesso a antigos latifundiários".

Na CRFB, encontram-se, no seu art. 6, os direitos sociais assim descritos: "a educação, a saúde, a alimentação, o trabalho, a moradia, o transporte, o lazer, a segurança, a previdência social, a proteção à maternidade e à infância, a assistência aos desamparados (...)" (HÜLSE, 2018).

Embora o problema seja histórico, somente no ano de 2000, por intermédio da Emenda Constitucional n. 26, o direito à moradia é reconhecido como direito fundamental e positivado na Constituição (MACHADO, 2017a). Sobre o histórico no país:

As primeiras tentativas de solucionar a questão habitacional brasileira datam de 1946, quando foi criada por meio do Decreto-Lei n. 9.218/46 (BRASIL, 1946), a Fundação da Casa Popular, considerada o primeiro órgão federal brasileiro, cuja finalidade era centralizar a política de habitação. Contudo, não logrou êxito e foi extinto em 1963, principalmente pela falta de recurso para 
Ainda sobre a situação no Brasil, Haglund; Stryker (2015, p. 14) leciona que "apesar dos investimentos consideráveis do governo federal, o Brasil luta contra um enorme déficit habitacional e milhões de pessoas em todo o país vivem em assentamentos irregulares", ainda, entendendo tal realidade, é importante mencionar as definições perante o ordenamento brasileiro, do que o direito à moradia é. Sobre a Moradia, elucida-se:

\begin{abstract}
A moradia é algo básico e elementar ao cidadão. É o lugar onde o cidadão e os demais membros do grupo familiar reúnem-se para celebrar as vitórias e reestabelecer as energias para as batalhas cotidianas. É o local de intimidade e aconchego. Contudo, mesmo sendo decisivo para o desenvolvimento da personalidade do cidadão, esse direito é negado a uma parcela gigante da população (MACHADO, 2017a, p. 231).
\end{abstract}

Compreendendo tal realidade, é necessário verificar que o Brasil conta com um Plano Nacional de Habitação que estima que para solucionar o déficit de habitação no país, será necessário construir ainda 31,3 milhões de novas habitações. Tal plano é audacioso e, infelizmente, não mostra-se frutífero e ágil o suficiente, considerando os dados dos últimos anos - podendo ainda ter sido mais agravado com a crise da COVID-19 (MACHADO, 2019).

É claro que um problema histórico não pode ser resolvido da noite para o dia, pois demanda ações engajadas do legislador, políticas públicas efetivas e grandes investimentos (MACHADO, 2019).

Fruto de uma histórica evolução e na intenção de permitir um desenvolvimento mais igualitário, ordenado e acessível a Lei no 13.465 trouxe uma possibilidade de Regularização Fundiária Urbana (Reurb), diferente das legislações anteriores. A lei menciona diversas vezes sua intenção de assegurar condições urbanísticas e ambientais em relação à situação de ocupação informal anterior, explicitando assim o respeito ao preceito fundamental da dignidade da pessoa humana. Necessário, é claro, explicitar que a Lei n 13.465 não é para aquisição de primeiro lar, diferente disso, é uma possibilidade simplificada de regularização, possibilitando e facilitando a moradia adequada, mencionada no início do presente trabalho.

Desse modo, a Reurb

[...] tem como principal objetivo garantir que o Estado [...] forneça aos cidadãos uma moradia adequada, ou seja, assegurar em condições mínimas uma vivência com dignidade e segurança e as devidas medidas de urbanização, ambientais e sociais. Com isso, nutre-se a ideia de uma efetiva regularização dos núcleos urbanos informais. Para tanto, o art. 14 da Lei ${ }^{\circ}$ 13.465/2017 informa que poderão requerer a Reurb, além dos entes públicos, os beneficiários, os proprietários, loteadores ou incorporadores, bem como a Defensoria Pública e o Ministério Público (PERSSON, PEREIRA, SCHNEIDER, BERWIG, 2019, p.4).

O instituto jurídico da Regulamentação Fundiária parece interessante e uma ferramenta Ponto de Vista Jurídico | Caçador | v.10 | nº 1 | p. 121 - 137| jan.jun. 2021 
que permeia diversos órgãos e camadas da sociedade a obter a regularização, efetivando o direito à moradia adequada.

Fica evidente ainda que a camada mais baixa da sociedade é a que mais sofre e suporta na vida diária a falta de habitação, as estatísticas mostram, inequivocamente, o grande desafio do Brasil, como nação, para resolver o problema do déficit habitacional (MACHADO, 2019).

\section{CONSIDERAÇÕES FINAIS}

Considerando o histórico apresentado, pode-se verificar com facilidade que a efetivação do direito à moradia é um desafio de escala global que permeia todos os continentes, em maior ou menor grau. A terra ocupa um papel de destaque na sociedade, historicamente sendo extremamente importante e concentrado na mão de uma minoria.

A noção de se ter direitos sobre um espaço exclusivo de terra é tão antiga quanto ele próprio. $\mathrm{O}$ direito à moradia abrange uma miríade de direitos garantidos pela legislação, como direito positivo.

Os mais pobres, em todo o mundo, enfrentam dificuldades em relação à moradia. A realidade brasileira parece ser privilegiada em alguns aspectos, a ponto da autora Shivani Chaundhry mencionar em seu texto de "The Human Right to Adequate Housing in India: Obstacles and Challenges" a possibilidade de usucapião (assim como no Brasil) como um possível avanço na realidade indiana.

Além disso, do ponto de vista legislativo, aparentemente os brasileiros estão mais protegidos pelo sistema jurídico do que na Noruega, onde não há regulação específica sobre o tema. Já a realidade da Nova Zelândia parece ser semelhante àquela vista no Brasil, onde as minorias têm maiores dificuldades em relação à moradia. Demonstrou-se ainda que o problema relacionado à efetivação do direito à moradia no país vem de longa data; inclusive, até o final da década de 1980, várias formas de assistência financeira do Estado permitiam que famílias de baixa renda construíssem ou adquirissem casas.

Em uma rápida comparação com a África do Sul, o Brasil aparenta ser levemente mais miscigenado e, portanto, não necessariamente separa os moradores de determinados locais por sua cor, ou ainda, estudos publicados sobre tal realidade não foram localizados pelo autor, o que inviabiliza uma adequada ponderação sobre a temática.

No cenário das Américas, a realidade é inequívoca. Como mencionado no texto, a questão da realidade americana, de um país rico, que teve destaque por conta da premiação do Oscar, Nomadland, retrata justamente a questão habitacional nos Estados Unidos, onde a vida 
nos $R V s$, para alguns, tornou-se mais do que apenas uma opção de recreação mas uma necessidade.

$\mathrm{Na}$ esfera nacional, apesar do histórico de desigualdade, comunidades ex-escravizadas com restrições e facilitação ao acesso a antigos latifundiários, alguns avanços se deram, em especial, no campo do direito, positivando o direito à moradia.

Apenas o tempo irá poder trazer os resultados para que, com os dados e depoimentos, seja possível fatidicamente comprovar a eficácia da Lei Federal 13.465/2017 que regulamenta a Regularização Fundiária (Reurb) no Brasil, como um dos instrumentos para facilitação do direito em tema, observando por seu histórico, a Lei que regulamenta a Reurb é um marco inovador e progressista no campo dos direitos sociais garantidos aos brasileiros.

\section{REFERÊNCIAS}

ASSEMBLÉIA GERAL DA ONU. Declaração Universal dos Direitos Humanos. Nações Unidas, 217 (III) A, 1948, Paris, art. 1, Disponível em: http://www.un.org/en/universaldeclaration-human-rights/. Acessado em 26 mar. 2021.

CHAUNDHRY, Shivani. The Human Right to Adequate Housing in India: Obstacles and Challenges. Georgetown Journal of International Affairs. 2019. Disponível em: https://www.georgetownjournalofinternationalaffairs.org/online-edition/2019/3/22/thehuman-right-to-adequate-housing-in-india-obstacles-and-challenges. Acessado em 19 mai. 2021.

CHENWI, Lilian. Implementation of Housing Rights in South Africa: Approaches and Strategies. Osgood Hall Law School at York University Journal of Law and Social Policy. vol.24-2015. Disponível em: https://digitalcommons.osgoode.yorku.ca/cgi/viewcontent.cgi? article=1209\&context=jlsp. Acessado em: 20 mai. 2021.

ESCRITÓRIO DO ALTO COMISSÁRIO DAS NAÇÕES UNIDAS PARA OS DIREITOS HUMANOS. Norway. 2015. Disponível em:

https://www.ohchr.org/Documents/Issues/Housing/Homelessness/States/29102015-

Norway.pdf. Acessado em: 20 mai. 2021.

ESTEVES, Julio. Sobre a Relação entre o Direito Natural e o Direito Positivo em Kant. O que nos faz pensar, [S.1.], v. 21, n. 32, p. 147-166, dec. 2012. ISSN 0104-6675. Disponível em: http://www.oquenosfazpensar.fil.puc-rio.br/index.php/oqnfp/article/view/380. Acesso em: 03 Jun 2021.

FAHRA, Leilani. End of Mission Statement: Visit of the Special Rapporteur on the right to adequate housing to New Zealand. Escritório do Alto Comissário das Nações Unidas para os Direitos Humanos, 2020. Disponível em: https://www.ohchr.org/EN/NewsEvents/Pages/DisplayNews.aspx?NewsID=25574\&LangID= E. Acessado em: 21 mai. 2021. 
GERALDELLI, Bruno. Direito Constitucional III: Direitos Sociais e Direitos de Nacionalidade. 1 ed. [S.L.]: [s.n.], 2019.

HAGLUND, LaDawn; STRYKER, Robin. Closing the Rights Gap: From Human Rights to Social Transformation. 1. ed. [S.L.]: University of California Press, 2015. p. 1-392.

HÜLSE, Levi. A Contribuição do Associativismo para a Sustentabilidade Ambiental, Econômica e Social: Análise da Experiência Brasileira e Estrangeira. Tese (Curso de Doutorado em Ciência Jurídica) - Universidade do Vale do Itajaí - UNIVALI. Blumenau. 241 f. 2018.

LAWTEACHER. Right to Adequate Housing in India. 2013. Disponível em: https://www.lawteacher.net/free-law-essays/constitutional-law/right-to-adequate-housing-inindia-constitutional-law-essay.php?vref=1. Acessado em 19 mai. 2021.

MACHADO, Claudiomar Luiz. A habitação no Brasil e possíveis soluções para reduzir o déficit. In CASTRO, Matheus Felipe; PATERNO, Andrey Luiz. Problemas de direitos fundamentais civis. Joaçaba: Editora Unoesc, 2017a

Disponível em:

https://www.unoesc.edu.br/images/uploads/editora/problemas_de_direitos_fundamentais_civi s.pdf. Acessado em 12 mai. 2021.

. Constitucionalização do direito de propriedade: a Necessidade de evolução do Conceito de Função social da propriedade rural frente ao direito ao desenvolvimento. In JEREMIAS, Jucélia Fátima Seidler, (org.) Temas sobre a constitucionalização dos direitos fundamentais: um debate crítico. Joaçaba: Editora Unoesc, 2017b. Disponível em: https://www.unoesc.edu.br/images/uploads/editora/Temas_sobre_a_constitucionaliza\%C3\%A 7\%C3\%A3o_dos_direitos_fundamentais.pdf. Acessado em 19 mai. 2021.

Direito Fundamental à Moradia: Uma abordagem teórica e prática. Rio de Janeiro: Lumen Juris, 2019.

NAÇÕES UNIDAS. Objetivos de Desenvolvimento Sustentável. Disponível em: https://brasil.un.org/pt-br/sdgs. Acesso em 03 jun. 2021.

NEW YORK CITY BAR. Report by The International Human Rights Committee of The New York City Bar Association: Advancing the Right to Housing In The United States. 2016. Disponível em: https://www2.nycbar.org/pdf/report/uploads/20072632-

AdvancingtheRighttoHousingIHR2122016final.pdf. Acessado em 20 mai. 2021.

PERSSON, Rodrigo; PEREIRA, Marília Rodrigues; SCHNEIDER, Eliete Vanessa; BERWIG, Aldemir. O DIREITO SOCIAL À MORADIA DIGNA E A REGULARIZAÇÃO FUNDIÁRIA URBANA - REURB COMO MEIO DE EFETIVAÇÃO. Anais da XX Jornada de Extensão UNIJUÍ (Salão do Conhecimento 2019). 2019. Disponível em: https://publicacoeseventos.unijui.edu.br/index.php/salaoconhecimento/issue/view/210. Acessado em 21 mai. 2021.

RIBEIRO, Djamila. Pequeno Manual Antirracista. 1 ed. [São Paulo]: Companhia das Letras, 2019. 
SANGHERA, Balihar; SATYBALDIEVA, Elmira. Ethics of property, illegal settlements and the right to subsistence. International Journal of Sociology and Social Policy, 2012.

SAULE JÚNIOR, Nelson; CARDOSO, Patrícia de Menezes. O Direito à Moradia no Brasil. Relatório da Missão Conjunta da Relatoria Nacional e da ONU 29 de maio a 12 de junho de 2004 - Violações, Práticas positivas e Recomendações ao Governo Brasileiro. São Paulo: Instituto Pólis, 2005. 160p. Disponível em: https://www.suelourbano.org/wpcontent/uploads/2017/09/UN-Relatoria-Direto-a-Moradia-no-Brasil-2004.pdf. Acessado em 19 mai. 2021.

SOUTH AFRICAN HUMAN RIGHTS COMMISSION. The Right To Adequate Housing Factsheet. 2016.2 Disponível em: https://www.sahrc.org.za/home/21/files/Fact\%20Sheet\%20on\%20the\%20right\%20to\%20ade quate\%20housing.pdf. Acesso em 20 de mai. 2021.

VOX. Why South Africa is still so segregated. Youtube, 19/04/2021. Disponível em: https://www.youtube.com/watch?v=NVH7JewfgJg. 